\title{
Student Achievement in an Introductory Biology Course: As- sessing Grade Motivation and Study Log Metacognition
}

\author{
Gail P. Hollowell ${ }^{*}$, Dwayne T. Brandon², and Wendy H. Grillo' \\ ${ }^{1}$ Department of Biology and ${ }^{2}$ Department of Psychology, North Carolina Central University, 1801 Fayette- \\ ville Street, Durham, NC 27707, USA
}

Received: May 27, 2013 / Accepted: August 1, 2013

\begin{abstract}
As college educators, our main teaching goals are to increase student learning and improve student retention. This study describes how 54 science majors at a public, minority serving institution reflected on their study time, study activities, and overall grade motivation in a core-curriculum introductory biology course. Since 2005 , less than $50 \%$ of students enrolled in this course at our university earned a final grade of "C" or better. In the Fall semester of 2009, we administered a pre and post assessment using the Science Motivation Questionnaire (SMQ) a 30-item Likert-type instrument developed by Glynn and Koballa (2006) to better understand and address the student attrition from the introductory biology course. All 30 items from the SMQ were analyzed, but only 5 items relevant to grade motivation are presented in this paper. We also designed and implemented a weekly study log assessment tool for students to document their study time and study activities, wherein students submitted their study logs on a weekly basis during the course of this research study. Based on the number of study logs submitted and study time by each student, students were classified into either a high-metacognition or low-metacognition group. For our purposes, we defined metacognition as the awareness of one's own thinking process (Merriam-Webster, 2012). The high-metacognition group submitted $75 \%$ of their study logs and earned a grade in the top $25 \%$ of the class. The lowmetacognition group submitted only $25 \%$ of their study logs and earned a grade in the bottom $25 \%$ of the class. Thus both groups formed reasonable expectations for their overall class performance.
\end{abstract}

Keywords: Biology; metacognition; student achievement; study $\log$.

Abbreviations: Science Motivation Questionnaire (SMQ)

\section{Introduction}

The academic success of undergraduate students in introductory science courses can be influenced by numerous variables, such as external factors, personal abilities, luck, (van Etten, et al., 1998) or motivation to learn the material. Quantitative research has shown that with academic motivation, two types of goals - learning goals (becoming more competent) and performance goals (doing better than others) have received more attention than others. Of the two, it is believed that learning goals are more effective in motivating students to excel academically (van Etten, et al., 1998). Therefore it is expected that motivated students will find academic activities both relevant and worthwhile and will to try to derive the intended benefits from them (Brophy, 2004). Students demonstrate their levels of motivation to learn in many ways, including their class attendance, class participation, the amount of time spent studying, completion of assignments, asking questions, and seeking help or advice. In studying motivation to learn science, Glynn et al, (2009) examined how intensively students strive to learn science, and what beliefs, feelings, and emotions characterize them in this process.

The introductory science course is the first opportunity wherein students experience the academic rigor of college science (Daempfle, 2002) and according to the National Science Foundation the sciences have the highest attrition rates of any major (National Science Foundation, 1996). As college educators, our main teaching goals are to increase student learning and improve student retention for our science majors. Surveys of entering underrepresented freshman note that the intentions to major in and continue on to a STEM career are similar to the intentions of majority students, however once enrolled, underrepresented students are less likely to actually major in and complete a STEM major (Fleming, 2012). Equally important to science students is the goal of obtaining a grade that will advance their academic and professional careers (Soto and Anand, 2009).

A high percentage $(85 \%)$ of our science majors aspire to become medical doctors, dentists, pharmacists, and other pro- 
fessions that require an advanced degree in a science field. However, since the fall semester of 2005 , less than $50 \%$ of the science majors completing the introductory biology course at our university received a final course grade of "C" or better. Approximately $90 \%$ of the students enrolled in our institution are first generation college students, and the student body is predominately African-American. While our institution has increased the admission standards and reorganized the academic structure to improve retention and graduation rates over the past 3 years, during the course of this study the average SAT score for the combined Math and Critical Reading Sections was 852 (Math $=428$ and Critical Reading $=424$ ). This is compared to the national average combined Math and Critical Reading Sections of 1013 (Math $=515$ and Critical Reading $=498$ ). Given these facts, there is a great interest in having students successfully complete courses and retain what they have learned.

One approach we have used is the use of learning logs. Learning logs, henceforth referred to as study logs, were designed to emphasize the connection between student study habits and their academic outcomes. The notion of having our students write down their daily study activities for this course, detailing how they approached studying provided them with the opportunity to reflect on their own 'cognitive aspects of learning' (Commander and Smith, 1996). These metacognitive aspects of learning can play a critical role in successful learning and help instructors in introductory science classes determine the optimal frequency and type of studying among students. In this paper, we discuss the level of importance students placed on earning a high grade in this introductory biology course as an indicator of type of motivation. We also assessed how often students reported studying to learn the content covered in the course, and if the amount of study time correlated with their overall performance in the course as measured by final grade.

\section{Materials and Methods}

\section{Participants}

Students who participated in this pilot study were enrolled in the traditional face-to-face sections of the introductory biology course taught at our institution. Of the 54 students who chose to participate in this study (41 females and 13 males) there were 48 African Americans, 2 Asians, 2 Caucasian, and 2 reporting other race/ethnic affiliations. These students were evenly distributed between the two instructors. At the time of participation, 47 students were enrolled in their first semester of college, with 0 accumulated credits; 4 students reported having 1 to 15 credits; and 3 students reported having 16 credits or more. Participation in this study was not required for course credit, and students who participated in this course did not receive any preferential treatment or extra credit while enrolled in this course. Overall, ninety percent of the students elected to participate throughout the semester, but only complete cases were analyzed for this pilot study. Students were made aware that the data collected would not be analyzed until after their final grades were submitted in an effort to motivate students to be honest in their responses. This research study (IRB \# 1200892) was approved for implementation by our University's Institutional Review Board for the Protection of Human Subjects in Research.

\section{Course Overview}

This study took place at a public, minority serving institution located in the southeastern part of the US with an enrollment of 6,400 undergraduate students. Two professors with equivalent years of teaching experience have taught this course for the past seven years in similar classroom settings with the same textbook and common lecture and laboratory exams. The introductory biology course at our institution is the first core course for science majors and for those students who will be taking upperlevel courses in biology.

This course is offered every semester with an average of 5 sections with 24 students per section. Only those sections taught by 2 of the authors were included in this study. This 4 -credit hour course meets for 3 lecture hours and 2 laboratory hours each week over the course of a 15 -week semester. The content of this course includes an introduction to the scientific method, a brief survey of the history of biology, an introduction to the physical and chemical properties of biological molecules, a survey of cellular structure and function, and an introduction to the basic principles of genetics. Traditional laboratory exercises that reinforce lecture content are included in this course. Graduate Teaching Assistants (TAs) are utilized for laboratory assistance only as determined by the Departmental Chairperson each semester. This course is assessed by the following: four lecture exams; quizzes and assignments; weekly laboratory participation; two laboratory exams; and a comprehensive final exam.

\section{Science Motivation Questionnaire (SMQ)}

The Science Motivation Questionnaire (SMQ) is a 30 item, Likert-type instrument developed by Glynn and Koballa (2006). The SMQ which was used to measure students' thoughts and expectations of their overall performance in science courses as well as their beliefs in the relevance of science to their anticipated careers. This survey was selected because it contained the most items of authors' interest as it pertained to the students. In addition, this survey had been found to be reliable and related to criterion-validity measures (Glynn et al., 2009). The motivational constructs measured by this survey include intrinsic and extrinsic motivation, goal orientation, self-determination, self-efficacy, and anxiety (Glynn et al., 2009). We administered this survey to our students at the end of a regularly scheduled class period and the students were asked to write their University issued student identification number on the survey and answer all 30 items. Once students completed the survey, they were asked to place the completed survey in a designated box at the back of the classroom. All questionnaire items were analyzed, but 5 were specifically chosen for this paper because they were relevant to our study and grade motivation. The 5 items chosen were as follows:

- I like to do better than other students on the science tests 
- Earning a good science grade is important to me

- I expect to do as well as or better than other students in the science course

- I think about how my science grade will affect my overall grade point average

- It is my fault if I do not understand the science

\section{Study Log Instrument}

This study log instrument, which was created by the course instructors, included the students' name, section number and blocks for each day of the week, description of study activity, and amount of time spent studying (Figure 1). A copy of the study log was placed in the Blackboard ${ }^{\circledR}$ course shell for each section of the introductory biology course, and students completed these study logs on their own timeframe throughout the week. Every Monday, during the regularly scheduled class period, students placed their completed study logs in a designated box at the front of the classroom, prior to the start of lecture. For each week of the 15-week semester, students were asked to record their study time and provide a description of their study activities. At the end of the week, students would calculate and record their total time spent studying for this course in minutes on a study log. Submission of study logs was voluntary with the intent that students would be honest about their study habits and their study behavior would not be influenced.

The study log completion and submission was voluntary for all of the students and the data was not analyzed until all final grades were submitted and the due date for grade appeals had ended.

\section{Final Grades}

Grades for this course were calculated based on lecture exams $(40 \%)$, quizzes \& assignments (10\%), lab participation (15\%), lab exams (20\%), and a comprehensive final exam (15\%). Final grades for all students enrolled in the introductory biology course were obtained from our University Course Enrollment System for all semesters, including summers from Fall 2005 to Fall 2009.

\section{Results}

\section{Science Motivation Questionnaire}

A total of 54 students completed the survey both at the beginning and end of the 15-week semester. To determine whether or not our students were motivated to study science in this introductory biology course, we analyzed the responses of the 5 selected items that were referenced for grade motivation. From the beginning of the semester to the end of the semester, there was a $9.3 \%$ decrease for students liking to do better than other students on the science tests and a $7.4 \%$ decrease for students who expected to do as well as or better than other students in the science course. However, there was a $3.7 \%$ increase for students who thought about how their science grade would affect their overall grade point average and an $18.5 \%$ increase in students' admittance to it being their fault if they did not understand the science. Figure 2 shows similar trends of pre- and post- responses for all students of the top quartile for the $5 \mathrm{SMQ}$ items used to measure grade motivation.

\section{Study Logs}

In addition to the SMQ survey data, we also collected student study logs each week during the course of this study to determine the amount of time and types of study activities of each student as they self-reported the amount of time they spent studying for this course. Based on the study log responses, the students were clustered based on two variables: i) average number of minutes they reported studying the content and ii) number of study logs they submitted for analysis. The first cluster grouped students into quartiles based on the average number of minutes they reported studying over the entire semester. The second cluster grouped students based on the number of study logs submitted over the course of the semester.

Based on the top quartile ratings in both time studied as recorded on the student study logs and number of study logs submitted, these students were placed in the high-metacognition category. Similarly, based on the bottom quartile ratings in both time studied as recorded on the student study logs and num-

Student ID \#

Course/Section

Study Log for the Week of

\begin{tabular}{|c|c|c|c|}
\hline $\begin{array}{l}\text { Date } \\
\mathrm{mm} / \mathrm{dd} / \mathrm{yy}\end{array}$ & $\begin{array}{l}\text { Block(s) of time } \\
\text { (e.g. 9:15-9:25 am) }\end{array}$ & $\begin{array}{l}\text { Activity - please give details (ex: study group, } \\
\text { notecards, learning objectives, read textbook, } \\
\text { etc.) }\end{array}$ & $\begin{array}{l}\text { Time spent } \\
\text { (e.g. } 10 \text { minutes) }\end{array}$ \\
\hline & & & \\
\hline & & & \\
\hline & & & \\
\hline & & & \\
\hline & & & \\
\hline & & & \\
\hline & & & \\
\hline & & Total time in $\mathrm{m}$ & \\
\hline
\end{tabular}

Figure 1. Study Log Instrument For Students To Record Time Spent and Type of Study Activity. 


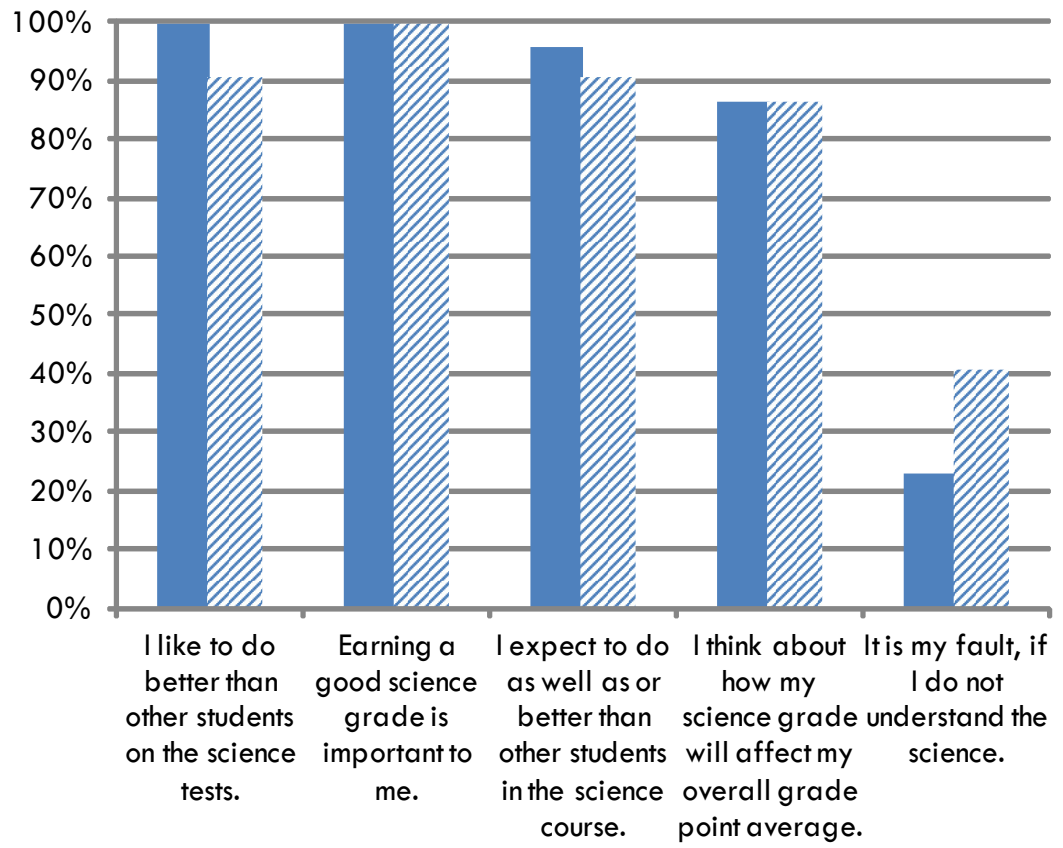

Pre Assessment

". Post Assessment

Figure 2. Pre and Post Survey Responses of the Top Quartile for the Five Student Motivation Questionnaire Items Used to Measure Grade Motivation.

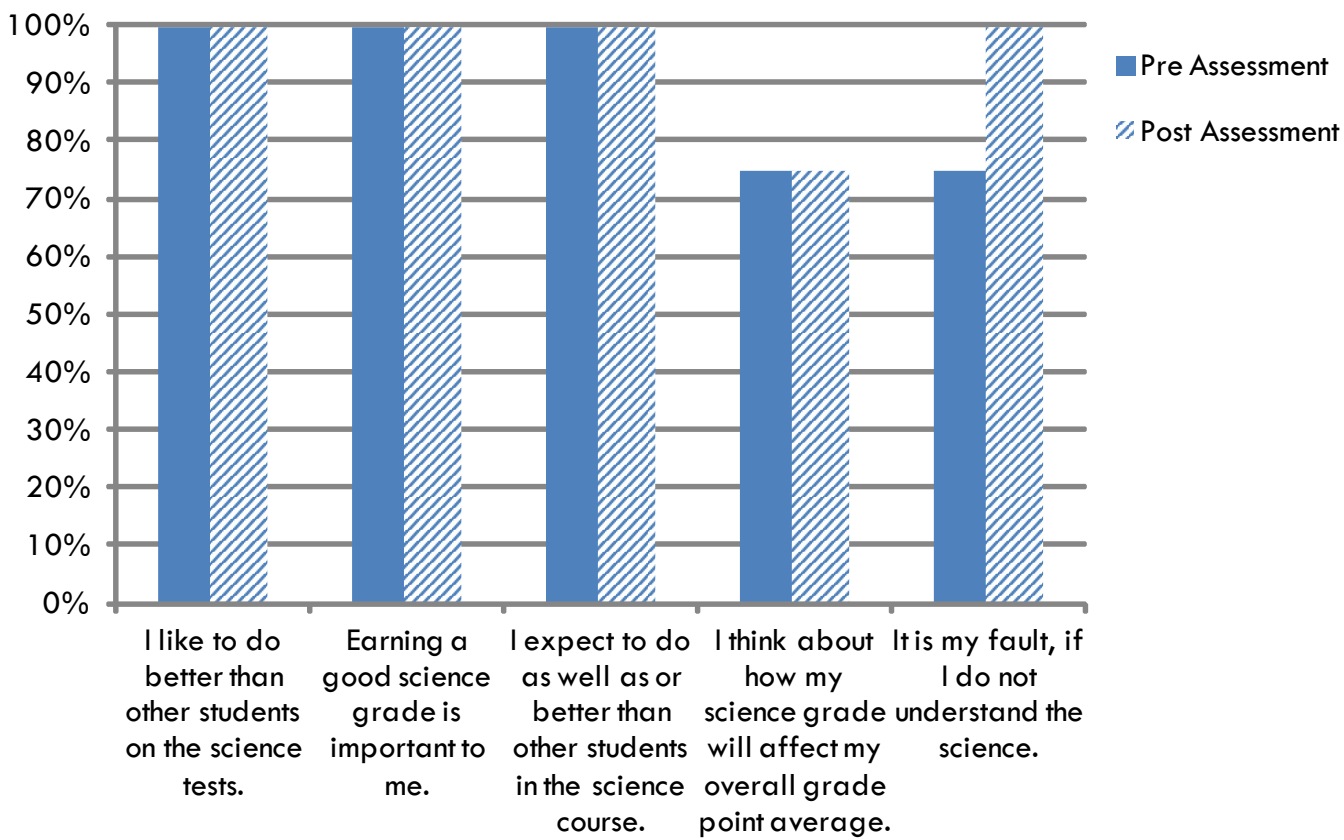

Figure 3. Pre and Post Survey Responses of the Bottom Quartile for the Five Student Motivation Questionnaire Items Used to Measure Grade Motivation.

ber of study logs submitted, these students were placed in the low-metacognition category. All students irrespective of metacognition category when asked on the SMQ if earning a good grade was always important indicated no difference between pre- and post- ratings (Table 1 ).

In the high-metacognition category, there was a 7\% downward trend in pre-and post- responses as to whether or not they like to do better than other students on science tests and on whether or not they expected to do as well as or better than other students in the science course. There was also a $7 \%$ upward trend in how often students thought about how their science grade will affect their overall grade point average. Surprisingly, there was a 33\% upward trend in students' admittance to it usually or always being their fault if they do not perform well in their science courses (Table 1; Figure 2).

In the low-metacognition category, there was an $8 \%$ down- 
Table 1. Summary Metacognition Table for the Top Quartile and Lowest Quartile Responses to the SMQ Grade Motivation Questionnaire Items.

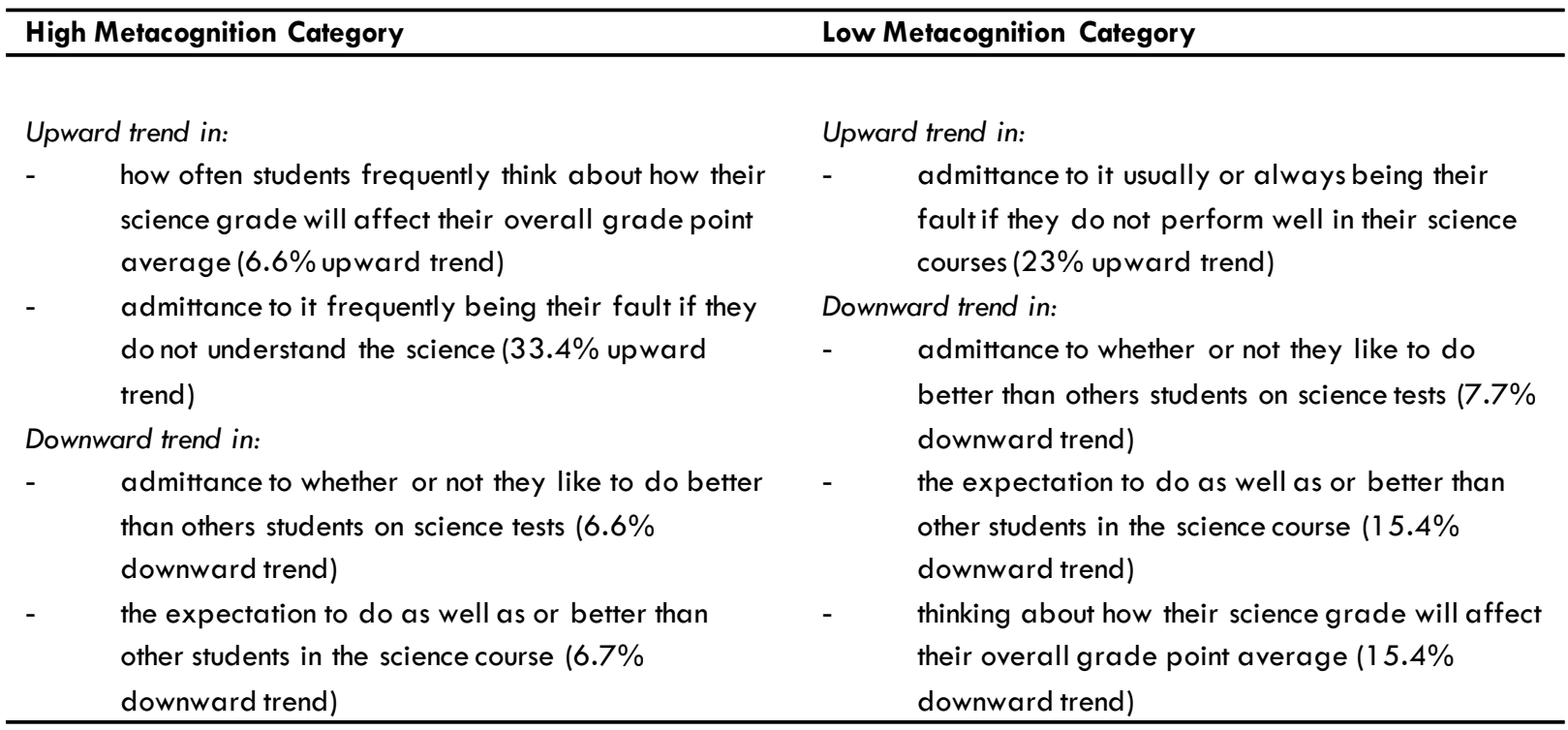

Likert-scale options "4-Usually" and "5-Always" were combined to define what we refer to as "Frequent".

Table 2. Examples of Actual Student Study Log Entries in Each of the Final Grade Categories.

\begin{tabular}{lcc}
\hline \multicolumn{1}{c}{ Student Recorded Study Activity - Week 7 } & Study Time (minutes) & Final Grade \\
\hline Prepared for lab exam (memorized statistics/metric conversion, cell & 210 & A \\
structure/functions, pH, biologically important molecules, and & \\
microscope/cell lab); lab exam preparation (read labs again); & \\
completed How to Study Homework & 231 & B \\
Looked over parts of the cell and unit conversion labs; studied lab & \\
quizzes; studied the acid and bases lab; read the study of science; & \\
completed exercises 3 and 6 in the How to Study Science book for & \\
Homework & 305 & 240 \\
Completed homework study group, and reviewed notes and labs & $*$ & $\mathrm{C}$ \\
Studied for the lab exam and completed homework & & D \\
$*$
\end{tabular}

* = Student did not submit a Study Log for this week.

ward trend in pre-and post- responses as to whether or not they like to do better than other students on science tests. There was a $15 \%$ downward trend on whether or not they expected to do as well as or better than other students in the science course and how often the students thought about how their science grade will affect their overall grade point average. Similar to the high metacognition group, there was a $23 \%$ upward trend in students' admittance to it usually or always being their fault if they do not perform well in their science courses (Table 1; Figure 3). These results suggest that over time the high metacognition group shifted to a more of an intrinsic motivation state. While this paper represents data from 1 semester, a detailed examination correlating study time and study activities to course performance over 3 semesters is forthcoming in a subsequent manuscript.

When analyzing the study log data for the average number of minutes studied over the entire semester, there were similar trends in pre- and post- responses on the SMQ for all students, regardless of quartile categorization. Comparing the number of study logs submitted, the data for all students when asked if earning a good grade was always important revealed that there was no difference between pre-post ratings, irrespective of quartile. There was, however, a $25 \%$ upward trend of the post- response for all students of the bottom quartile for the $S M Q$ item when asked if it were usually or always their fault if they did not understand the science (Figure 3).

\section{Examples of Study Log Entries}

After analyzing the study log entries, it was determined that it was not the amount of time spent studying, but perhaps the type of study activity that may have played a role in the students' overall class performance. Table 2 shows a reflection of study log entries and weekly study time in each of the final 
Table 3. Pearson Correlations between Final Letter Grade, Total Number of Study Log Completed, and Average Weekly Study Time.

\begin{tabular}{|c|c|c|c|c|}
\hline & & $\begin{array}{c}\text { Final Letter } \\
\text { Grade }\end{array}$ & $\begin{array}{l}\text { Total \# of Study } \\
\text { Logs Completed }\end{array}$ & $\begin{array}{c}\text { Average Weekly } \\
\text { Study Time }\end{array}$ \\
\hline \multirow[t]{4}{*}{ Final Letter Grade } & Pearson & 1 & $.433^{* *}$ & .102 \\
\hline & Correlation & & & \\
\hline & Sig. (2-tailed) & & .000 & .344 \\
\hline & $N$ & 91 & 91 & 88 \\
\hline Total Number of Study Logs & Pearson & $.433^{* *}$ & 1 & .080 \\
\hline \multirow[t]{3}{*}{ Completed } & Correlation & & & \\
\hline & Sig. (2-tailed) & .000 & & .460 \\
\hline & $\mathrm{N}$ & 91 & 91 & 88 \\
\hline Average Weekly Study & Pearson & .102 & .080 & 1 \\
\hline \multirow[t]{3}{*}{ Time } & Correlation & & & \\
\hline & Sig. (2-tailed) & .344 & .460 & \\
\hline & $\mathrm{N}$ & 88 & 88 & 88 \\
\hline
\end{tabular}

**. Correlation is significant at the 0.01 level (2-tailed).

grade categories from a randomly chosen week in the semester. The "A" student typically described the types of study activities completed on a weekly basis. In the example provided, the "A" student studied the assigned material, and then reviewed the work. The "B" student, whose study habits appeared to be similar to the "A" student, was very specific about what was studied but it is unclear whether or not these students were previewing or reviewing the information. The referenced 'How To Study Science' for the A and B students was a supplemental textbook packaged with required course material from McGraw Hill publishers. The "C" student indicated that they met with study group, but offered no details about what material was actually being studied. Whereas, the "D" student recorded that they completed homework and looked over the course material. This particular week, the "F" student did not submit a study log, but typical entries from students who earned an $F$ in the course, offered no detail about specific chapters or PowerPoint slides that had been read or these students would submit a blank study log (i.e., no reported study activities with " 0 " recorded minutes). These differences by grade indicate that these students with higher grades study and process material more elaborately than students with lower grades.

Table 3 shows the correlations between the final letter grade, total number of study logs completed, and average weekly study time. The Pearson correlation indicated that there was a statistically significant positive correlation between the final letter grade and the total number of study logs completed (Pearson correlation $=0.433$ ). These results suggest that completing a higher number of study logs encouraged more metacognition, which, in turn, positively influenced the students' final grades.

\section{Discussion}

The degree and quality of self-regulatory processes that students can exercise during academic studying depends on several key psychological dimensions of functioning, such as motivation, method, and time (Zimmerman, 1998). In higher education, students have different goals with respect to academic learning. For example, students who are deep processors vigorously engage in the content and relate new ideas to their prior knowledge. Students who are strategic processors focus on obtaining the highest grade possible and organize their time and efforts to maximize grades. Whereas students who are surface processors seek to only complete their assignments and tend to memorize the information (van Etten, et al., 1998).

In this study, students reflected on their study time, study activities, and were surveyed about their overall grade motivation in an introductory biology class. Of the 5 selected SMQ survey items related to grade motivation, the importance of earning a good grade in science both at the beginning and at the end of the semester had the highest number of positive responses, thus indicating that earning a good science grade was indeed a strong motivating factor for our students. This finding is consistent with an earlier report on freshmen beliefs about their academic motivation (van Etten, et al., 1998). These findings indicate that students in the highest quartile for metacognition showed an increase in learning metacognition. At the end of the semester, these students indicated a greater understanding of the connection between science class performance and GPA. They also indicated a greater responsibility for their own learning.

The study log data revelaed that although the students that earned a final course grade of an "A" in this course spent less time studying than the student who earned a final course grade of a "B", the student that earned the "A" had more comprehensive study techniques that likely led to a deeper understanding of the scientific content. Zimmerman suggests that as students' studying becomes more routine they can mentally organize the information without needing to create a formal outline (1998). Deep processors relate new ideas to their prior knowledge and everyday experiences. They link evidence and conclusions as they examine the logic of arguments (van Etten, et al., 1998). The type of study activity, the time spent on the activity, and the ability for the students to understand what they do not under- 
stand suggests that knowledge learned in primary school, and the ability to synthesize and utilize knowledge at the college level is usually at a much higher pace or level than students have previously experienced (Nordell 2009, Tanner 2012). Therefore, it can be very challenging for new college students to understand and be successful using this different model of higher education learning (Nordell 2009, Tanner 2012).

To gain further insight about study habits, our students were required to submit weekly study logs for the fall 2009 semester indicating the amount of study time dedicated to this course. Our students studied an average of 4 hours and 30 minutes each week for this 4-credit hour introductory biology course. It is the instructors' belief that this is not nearly enough time to adequately review the material presented from the previous lecture and complete the assigned readings for the upcoming lectures. Although this may not be surprising to college or university educators, the results of our study show that students and instructors have different perceptions as to how much effort is needed to learn the course material.

In our study, there was a statistically significant positive correlation between the numeric grade and the total number of study logs completed (Pearson correlation $=0.433$ ). Completing a higher number of study logs seems to encourage more metacognition, which in turn positively influenced the students' final grades. In addition, Soto and Anand (2009) reported that their students expressed a change in attitude regarding expected and performed study habits in a lower division Cell Biology core course. They suggested that although most students expected to spend a large amount of time studying, their commitments to other courses, outside work, or other personal matters prevented them from doing so. Similar distractions may have prevented our students that earned a final course grade of a " $D$ " and/or an "F" from dedicating more study time to this introductory Biology course. When comparing the percentages of final grade distribution from the fall semester of 2009 versus the cumulative semesters from fall 2005 through summer 2009, there was a $14 \%$ increase in the number of students completing General Biology I that received a final course grade of " $\mathrm{C}$ " or better. Although the study log data revealed consistent study patterns prior to an exam, very few students had consistent weekly study patterns throughout the semester. Examples of study strategies for students who performed well in the course included reading the assigned material prior to class, reviewing lecture notes after class, and identifying answers to the learning objectives. Students were placed in one of two categories: high-metacognition or low-metacognition. Students in the high-metacognition category submitted $75 \%$ of their study logs and earned a grade in the top $25 \%$ of the class. Students in the low-metacognition category submitted only $25 \%$ of their study logs and earned a grade in the lowest $25 \%$ of the class. Since this was the first time our students had been asked to record their daily study time and study activities in an introductory science course, this record keeping allowed the students to see and think about how they were learning science. Since our students are often unaware of how they learn, and to a lesser degree what they have learned, we believe the use of study logs promoted their metacognitive abilities and perhaps fostered academic success. The results from this work show that metacognition is important to academic performance and students with deeper levels of metacognition showed greater motivation for learning. Moreover, students with more elaborative study methods performed better when compared to students that studied with the non-elaborative methods. Future work will continue to look at what information needs to be logged for metacognition studies to address student science achievement. We will also look at the other SMQ items for this group and continue to use the SMQ on a larger scale.

\section{Acknowledgements}

The authors would like to gratefully acknowledge those individuals that helped with data entry, data verification, and data analysis.

\section{References}

Brophy J (2004) Motivating Students to Learn (2nd ed.) Mahwah, NJ: Erlbaum. pp 418.

Commander NE and BD Smith (1996) Learning logs: A Tool for Cognitive Monitoring. Journal of Adolescent \& Adult Literacy 39: 446453.

Daempfle PA (2002) Faculty Assumptions about the Student Characteristics Required for Success in Introductory College Biology. Bioscene 28(4): 19-33.

Fleming J (2012) Enhancing minority student retention and academic performance: What we can learn from program evaluations. California: Jossey-Bass (2012).

Glynn SM, G Taasoobshirazi, and P Brickman (2009) Science Motivation Questionnaire: Construct Validation with Nonscience Majors. Journal of Research in Science Teaching 46: 127-146.

Glynn SM, and TR Koballa Jr. (2006) Motivation to learn in college science. In: JJ Mintzes and WH Leonard (eds.), Handbook of College Science Teaching. National Science Teachers Association Press, pp. $25-32$.

Merriam-Webster (2013) www.merriam-webster.com/dictionary/ metacognition (retrieved September 5, 2012.

National Science Foundation (1996) Shaping the future: New Expectations for undergraduate education in science, mathematics, engineering, and technology. A Report by the Advisory Committee to the National Science Foundation Directorate for Education and Human Resources.

Nordell SE (2009) Learning How to Learn: A Model for Teaching Students Learning Strategies. Journal of College Biology Teaching 35 (1): 34-47.

Soto JG and S Anand (2009) Factors Influencing Academic Performance of Students Enrolled in a Lower Division Cell Biology Core Course. Journal of the Scholarship of Teaching and Learning 9 (1): 64-80.

Tanner, KD (2012) Promoting Student Metacognition. Cell Biology Education - Life Science Education 11: 113-120.

Van Etten S, M Pressley, G Freebern, and M Eschevarria (1998) An Interview Study of College Freshmen's Beliefs About Their Academic Motivation. European Journal of Psychology of Education 13 (1): 105-130.

Zimmerman, BJ (1998) Academic Studying and the Development of Personal Skill: A Self-Regulatory Perspective. Educational Psychologist $33(2 / 3):$ 73-86. 